\title{
Collaborative tools: computer science students' skills versus software industry needs
}

\author{
Fuensanta Medina-Dominguez ${ }^{1, *, \dagger}$, Maria-Isabel Sanchez-Segura ${ }^{1}$, \\ Ana Moreno ${ }^{2}$ and Daniel Santin ${ }^{3}$ \\ ${ }^{1}$ Computer Science and Engineeering Department, Carlos III University of Madrid, Avenida de la Universidad 30, \\ 28911 Leganés, Madrid, Spain \\ ${ }^{2}$ School of Computer Science, Universidad Politécnica de Madrid, Campus de Montegancedo s/n, Madrid, Spain \\ ${ }^{3}$ Faculty of Economics, Universidad Complutense de Madrid, Campus de Somosaguas, 28223, Pozuelo de Alarcon, \\ Madrid, Spain
}

\begin{abstract}
Software companies encourage and further the use of collaborative tools and skills at the work place in pursuit of the benefits of their use: they improve communication, productivity and efficiency, and competitiveness. Besides, undergraduate and graduate software engineering computing curricula recommend subjects related to effective cooperative working and group learning. In order to align industry needs and curricula recommendations, universities should provide graduates with the collaborative knowledge and skills that will be required when they finish their degrees and join the labor market. In this scenario, we asked three questions: Are collaborative tools beneficial to software projects? Is it easier for graduates with knowledge and skills of collaborative tools to find a job? Do enterprises use collaborative tools as a marketing strategy for the recruitment process or are they really empowering their employees to use collaborative tools? We devised a survey which was administered to 86 recent computer science graduates. We applied statistical techniques to analyze the responses. We conclude that graduates skilled in the use of collaborative tools do find it easier to get jobs, and companies are not only looking for people with collaborative skills but also regularly use collaborative tools in their work processes. Copyright (C) 2015 John Wiley \& Sons, Ltd.
\end{abstract}

\section{INTRODUCTION AND BACKGROUND}

Collaboration can be defined as a recursive process where two or more people or organizations work together toward a number of common goals - for example, a creative intellectual endeavor - by sharing knowledge, learning and building consensus [1]. Collaborative environments, known as computer supported collaborative work (CSCW), are defined by Tschang and Della [2] as 'multiuser software applications that enable people to co-ordinate and collaborate in a common task or goal without being in close proximity either spatially or temporally'. In a broad sense, CSCW provides technological support for humans involved in collaborative group communication and work processes [3]. In this context, collaboration refers to the joint work of a group of people on shared objects, where people share common goals and are jointly responsible for the outcome [4]. The new

*Correspondence to: Fuensanta Medina-Dominguez, Computer Science and Engineering Department, Carlos III University of Madrid, Avenida de la Universidad 30, 28911 Leganés (Madrid), Spain.

${ }^{\dagger}$ E-mail: fmedina@inf.uc3m.es 
opportunities for collaboration provided by information technologies provide new forms of business organization [5], which is why work teams nowadays use quite a number of collaborative tools that support collaborative processes and capabilities.

Computer supported collaborative work is considered to be particularly important in technological areas like Web 2.0 and social media. Web 2.0 is defined as 'technologies that enable users to communicate, create content and share it with each others via communities, social networks and virtual worlds more easily than before' [6]. And social media are defined as 'a group of Internetbased applications that build on the ideological and technological foundations of Web 2.0 and that allow the creation and exchange of user-generated content' [7].

Web 2.0 and social media open up new opportunities for the business. For example, they enhance communication, interaction, learning, and collaboration [8]. Thanks to Web 2.0 users can easily find and collaborate with other employees that have similar expertise, are working on similar problems, or have the expertise that they need to complete a task [9]. All these improvements result in benefits for the business such as the adoption of innovative products and services, better access to knowledge, lower cost of doing business, and higher revenues [10].

Teamwork skills are one of the mainstays of the collaborative culture: 'The lack of teamwork contributes to loss of money, loss of direction, slow growth or shrinking, and smaller market share' [11]. Teamwork is particularly important in the software industry, where a high level of collaboration is critical throughout the entire development process.

This is one of the reasons why software companies have for some years been promoting and enhancing the use of collaborative environments, which are assumed to provide important competitive advantages [12]. For example, a study conducted in 2006 by IBM (Armonk, NY, USA) discusses how chief executive officers stressed the overwhelming importance of collaborative innovation, particularly beyond company walls, while at the same time recognizing that their organizations are not collaborating nearly enough [13]. Also, Frost and Sullivan [14] demonstrated the impact of collaboration on business, in particular on financial, performance, customer satisfaction, labor productivity, product quality, product development, and innovation.

Computer supported collaborative work can be addressed from several angles: arts and humanities, for example [15]; social science [16] [17]; and technology, for example [16] [18]. We have reviewed the literature related to CSCW looking for well-established knowledge in the field of software development over the last five years. To do this, we searched the Web of Science in the science technology domain, where we found 185 papers focusing on software development. These papers address different issues:

- CSCW platforms or tools (17 papers), describing the foundations and experiences of developing CSCW tools. Some examples are [18-21].

- Metamodels and design (31 papers), proposing models and designs of CSCW environments and platforms. For example [22-25].

- Collective intelligence ( 3 papers), explaining the importance of using collective intelligence, where the interpretation of context information can be harnessed as input for context-aware applications, especially for group collaboration. Some examples are [26-28].

- Education, learning or teaching experiences (72 papers), exploring the function and connection of $\mathrm{CSCW}$ in education, and how the educational process and outcomes can benefit from the use of CSCW environments. Some examples are [29-33].

- Applications in enterprises (62 papers), describing the applications, benefits, problems, and specific features of CSCW tools and environments in enterprises. Some examples are [34-38].

In general, this $\mathrm{CSCW}$ literature highlights some relevant benefits of using collaborative environments:

- Improve communication: CSCW tools provide communication channels. Depending on the tool used, the channels can be synchronous or asynchronous. Employees can use the communication channels to communicate efficiently, connecting with the right people to get quick answers to their questions and reducing point-to-point conversations [34] [37] [39-41]. 
- Increase productivity and efficiency: $\mathrm{CSCW}$ tools provide a common repository, which is critical for efficient project management. Also, CSCW sets up project workspaces, where team members can share project knowledge, participate in real-time brainstorming, make decisions, and improve the quality of meetings, products and services. All these reduce the time and costs of software development. Cost cutting is not a direct benefit of $\mathrm{CSCW}$; it is an indirect benefit of using CSCW [9] [29] [30] [35] [41-43].

- Improve competitiveness: CSCW improves companies' competitiveness by providing new channels of communication with employees and stakeholders, encouraging innovation, and opening up new business opportunities [37] [44]. The benefits of customer use of social media benefits include, for example, an average $20 \%$ increase in the number of successful innovations [34].

On the other hand, knowledge of collaborative capabilities and tools improves job opportunities. Han et al. [45] discuss this issue, claiming that employees with CSCW skills are well-positioned because enterprises are betting on collaborative environments and skills. Therefore, people with knowledge of collaborative work are a valuable asset for companies because they are capable of creating innovative ideas through communication and interaction with other people.

The aforementioned benefits drive companies to demand employees that are not only knowledgeable about the organization's core business but also have collaborative skills [46] [47]. The shortage of professionals with collaborative skills drives companies to look for incentives to motivate employees to participate in enterprise social networking systems [48]. The origin of the lack of collaborative skills is graduate education. Nevgi et al. [49] claim that a serious problem is that, university students' cooperative work capabilities are generally weak. So, it is not uncommon to find studies that conclude that industry and academia should work together to assure that the collaborative skills required by employees to perform their jobs are taught at university [46] [50]. Therefore, universities face the challenge of training students not only in the foundations of computer science or software engineering but also in the latest technologies and skills required by the labor market, as these will be essential requirements to which companies will attach importance when recruiting new graduates.

The Undergraduate Software Engineering [51] and the Graduate Software Engineering [52] Computing Curricula are aligned with this tendency and recommend that students should take subjects related to effective cooperative working and group learning. This will be a useful knowledge, helping future software practitioners learn the mechanics and dynamics of effective teamwork and collaborative environments and tools as part of their undergraduate and graduate education.

As we have already discussed, there is a relevant body of CSCW knowledge in the area of software development. However, we have not found reports that analyze the opinions of the graduates, with respect to the benefits of their CSCW acquired skills' at workplace. With the aim of contributing to this field and as a first proof of concept, we have surveyed 86 recent computer science graduates from the Carlos III University in Madrid (UC3M) for three purposes: check whether the graduates perceived the benefits of collaborative tools identified in the literature; find out whether graduates thought that the knowledge learned about collaborative skills helped them to find or improved their jobs; and discover whether their employers attach importance to and promote the use of collaborative tools and skills.

The remainder of this paper discusses how we have addressed this issue. Section 2 shows how $\mathrm{CSCW}$ is taught at UC3M. Section 3 details the survey. Section 4 reports and discusses the results. Finally, Section 5 describes the future lines of work and outlines the conclusions.

\section{COMPUTER SUPPORTED COLLABORATIVE WORK AT THE CARLOS III UNIVERSITY}

Computer supportive collaborative work is taught at UC3M as part of an elective course unit called Application of New Technologies in Enterprises (ATIE). This course is taught during the final year of the BSc in Computer Science degree program. Despite the fact that ATIE is an elective, it has a higher student count, at about 80, than other final-year elective subjects, which attract around 40-50 
students on average. Final-year students have already developed software projects during their degree course but have not used collaborative tools. The aim of ATIE is for students to learn about collaborative capabilities, environments, and tools. Students are traditionally taught environments and tools with reference to their functionalities. The strategy applied in ATIE is different; it is based on teaching the functionalities and capabilities of a collaborative tool using software engineering best practices. In this way, reverse engineering is used to transform the user manual of a commercial collaborative tool into a set of analysis and design products that students will have managed routinely during their degree program. In particular, students use object-oriented techniques such as UML, use cases and classes and sequence diagrams to explain the features of a collaborative tool. For more details [53].

Before addressing the development of collaborative projects, ATIE students learn about the features of collaborative skills and the functionalities of different collaborative tools: Community Server, Joomla!, Xoops, Moodle, Sakai, Blackboard and Microsoft Sharepoint, studying technologies like wikis, blogs, social network sites, open or private communities, and discussion forums. Students then work in five-member teams to develop their collaborative projects. Most use a Microsoft Sharepoint collaboration portal to do this. Following the aforementioned teaching strategy, they use software engineering models to define this portal. Students play different roles during the development of the practical assignments: project manager, analysts, and programmers. Students collaborate with the members of their own team and other teams through a web-based collaboration portal used to answer group questions and share tricks and ideas.

\section{METHOD}

In this section, we describe the aims and main characteristics of the survey.

\subsection{Survey development}

The aim of this survey is threefold. First, we want to check the benefits of CSCW discussed in the literature. Second, we want to find out if graduates who have learned collaborative capabilities and tools have a better chance of finding a job (either a first job or a new job for graduates who were already working in industry at the time of taking the subject). The third aim is to confirm whether industry really attaches importance to and promotes collaborative skills.

To be more precise, this survey focuses on assessing these three objectives:

- Objective 1: Graduates rate the benefits of using collaborative tools. The aim of this objective is to check whether recent graduates are aware of the advantages offered by CSCW and whether these advantages can be observed during the CSCW project development part of ATIE.

- Objective 2: Graduates rate whether collaborative skills help them to find a job. Our aim is to check whether knowledge of collaborative skills and tools helped recent graduates to find or improve their jobs.

- Objective 3: Graduates rate whether companies really do use collaborative tools or this is just an enterprise advertising or marketing strategy. The aim is to check whether recent graduates who were hired by companies, thanks to their knowledge of collaborative skills and tools, used this type of technology in their routine work or it was just a marketing ploy used by leading technology enterprises to attract potential staff.

The process enacted to administer the survey was divided into three phases: preparation, completion, and collection. A description of these phases follows.

a. Preparation phase. In this phase, we defined the objectives, and then formulated the statements to check each objective. The survey included 16 items or statements. Of these items, only seven served the purpose of analysis and the others were control items used to check for consistency. Table I summarizes the objectives covered by the items (column 1), the main and control items (columns 2 and 3), and the rationale underlying the relationship between the main and control items (column 4). 
Table I. Summary of objectives, survey items, rationale, and expected benefits.

\begin{tabular}{|c|c|c|c|}
\hline & Statement & Control Items & Rationale \\
\hline \multirow[t]{6}{*}{$\begin{array}{l}\text { Objective 1: Identify the benefits } \\
\text { of using collaborative tools }\end{array}$} & $\begin{array}{l}\text { S1. After studying ATIE, I think } \\
\text { that collaborative tools will } \\
\text { improve communication among } \\
\text { team members. }\end{array}$ & $\begin{array}{l}\text { S6. Collaborative environments enable } \\
\text { synchronous and/or asynchronous } \\
\text { interaction among users. } \\
\text { S7. Collaborative environments connect } \\
\text { people, teams, and knowledge across } \\
\text { business processes. } \\
\text { S8. Collaborative environments help to } \\
\text { integrate information from different } \\
\text { systems or departments. }\end{array}$ & \multirow[t]{2}{*}{$\begin{array}{l}\text { These items control the CSCW features } \\
\text { learned by recent graduates. Responses } \\
\text { to these items should be consistent with } \\
\text { the responses to Statement S1. If not, } \\
\text { we should analyze the items to see where } \\
\text { the discrepancy lies. }\end{array}$} \\
\hline & & $\begin{array}{l}\text { S12. Collaborative environments have } \\
\text { helped me organize, plan and } \\
\text { document projects. } \\
\text { S4. After studying ATIE, I understand } \\
\text { what a collaborative environment is. }\end{array}$ & \\
\hline & $\begin{array}{l}\text { S2. After studying ATIE, I think } \\
\text { that collaborative tools will improve } \\
\text { teamwork productivity. }\end{array}$ & $\begin{array}{l}\text { S12. Collaborative environments } \\
\text { have helped me organize, plan } \\
\text { and document projects. }\end{array}$ & \multirow{3}{*}{$\begin{array}{l}\text { This statement is related to planning } \\
\text { issues. If CSCW is useful for planning, } \\
\text { then it should lead directly to an improvement } \\
\text { in productivity. If the responses to S2 and S12 } \\
\text { are inconsistent, they should be analyzed to } \\
\text { identify the cause of the discrepancy and remove } \\
\text { the sample responses that are distorting the data. } \\
\text { These two statements are related to the promotion } \\
\text { of the use of CSCW in organizations. The } \\
\text { responses to these statements must be consistent } \\
\text { with the responses to S5. If there are any cases } \\
\text { where respondents agree with S15 and S16 and } \\
\text { disagree with S5, they should be removed from } \\
\text { the sample because the responses are inconsistent. }\end{array}$} \\
\hline & \multirow[t]{2}{*}{$\begin{array}{l}\text { S5. I would recommend } \\
\text { collaborative tools for teamwork. }\end{array}$} & $\begin{array}{l}\text { S15. I would use collaborative } \\
\text { environments at my company. }\end{array}$ & \\
\hline & & $\begin{array}{l}\text { S16. After learning the concepts } \\
\text { of a collaborative environment, } \\
\text { I feel capable of transmitting the } \\
\text { need for collaborative environments } \\
\text { and encouraging my colleagues to } \\
\text { work collaboratively. }\end{array}$ & \\
\hline & $\begin{array}{l}\text { S11. The use of collaborative tools } \\
\text { reduces project development time } \\
\text { and workload. }\end{array}$ & $\begin{array}{l}\text { S12. Collaborative environments } \\
\text { have helped me organize, plan } \\
\text { and document projects. }\end{array}$ & $\begin{array}{l}\text { Responses to statement } \mathrm{S} 12 \text { are related to planning } \\
\text { and project management. They should be } \\
\text { consistent with responses to } S 11 \text {, which is related to } \\
\text { savings in project development time and workload. }\end{array}$ \\
\hline
\end{tabular}

(Continues) 
Table I. (Continued)

\begin{tabular}{|c|c|c|c|}
\hline & Statement & Control Items & Rationale \\
\hline $\begin{array}{l}\text { Objective } 2 \text { : Identify the } \\
\text { relationship between } \\
\text { collaborative skills and } \\
\text { chances of finding a job }\end{array}$ & $\begin{array}{l}\text { S10. Knowledge of collaborative } \\
\text { environments has helped me find a } \\
\text { job more easily. }\end{array}$ & $\begin{array}{l}\text { No control item needed because } \\
\text { the statement is straightforward. }\end{array}$ & \\
\hline \multirow[t]{2}{*}{$\begin{array}{l}\text { Objective 3: Identify enterprise } \\
\text { attitude to collaborative tools } \\
\text { after employing graduates on } \\
\text { the strength of their } \\
\text { collaborative skills }\end{array}$} & $\begin{array}{l}\text { S9. Enterprises rate teamwork } \\
\text { knowledge and collaborative tools } \\
\text { positively. }\end{array}$ & $\begin{array}{l}\text { S3. After studying ATIE, } \\
\text { I have used collaborative } \\
\text { tools at enterprises. }\end{array}$ & $\begin{array}{l}\text { Statement S3 is related to the use } \\
\text { of CSCW in enterprises. If respondents } \\
\text { have used CSCW, it is because enterprises } \\
\text { promote the use of such tools. The responses } \\
\text { to S3 and S9 must be consistent. If there } \\
\text { are any cases where respondents agree with } \\
\text { S3 and disagree with S9, they should be } \\
\text { removed from the sample because the } \\
\text { responses are inconsistent. }\end{array}$ \\
\hline & $\begin{array}{l}\text { S14. The business environment } \\
\text { is moving toward the use of } \\
\text { collaborative tools. }\end{array}$ & $\begin{array}{l}\text { S3. After studying ATIE, } \\
\text { I have used collaborative tools } \\
\text { at enterprises. } \\
\text { S13. Collaborative tools are } \\
\text { tailorable to different types of } \\
\text { projects and business environments. }\end{array}$ & $\begin{array}{l}\text { S3 and S13 are related to the respondents' } \\
\text { opinion of whether CSCW (S3) platforms } \\
\text { can be tailored to different project types and } \\
\text { environments. Agreement with this statement } \\
\text { should be consistent with agreement with } \\
\text { S14, which states that companies are moving } \\
\text { towards the use of these environments because } \\
\text { CSCW is able to adapt the business to market } \\
\text { needs. If S13 and S3 were inconsistent } \\
\text { with S14, this could denote that companies } \\
\text { are not taking full advantage of CSCW, and } \\
\text { enterprises are not using these tools as leverage } \\
\text { to boost business. }\end{array}$ \\
\hline
\end{tabular}


The survey responses were given on a five-point Likert scale:

- No answer (N/A): 0

- Strongly disagree: 1

- Slightly disagree: 2

- Neutral: 3

- Slightly agree: 4

- Strongly agree: 5

The survey also returns qualitative information because there is a comments section under each item, which graduates can use to discuss their responses. Completion of the comments section is optional. We used the Google drive functionality to build the survey (The survey is available at: https://docs.google.com/forms/d/1-Whi-HfHyc95iOdqdxXek3dfLQ6bCBohz P9BzoVeqHA/viewform). The survey was anonymous, and participants had on-line access.

b. Completion phase. We created a mailing list containing all graduates who took the ATIE course unit during the 2011-2012 academic year. One year after they completed the subject, that is, in June 2013, we sent an e-mail asking former graduates to take a web-based survey within two months. The e-mail was sent to 103 graduates, but only 86 completed the survey.

c. Collection phase. We collected data in Microsoft Excel format. See Appendix A for the collected data.

\subsection{Demographics}

Survey respondents were 86 UC3M graduates representing a high response rate of $83.50 \%$. These graduates had taken the ATIE course unit described earlier during the 2011-2012 academic year.

Application of new technologies in enterprises students often take a part-time job as software environment programmers while they are studying, but, as already mentioned, they have no previous experience with collaborative environments.

In order to gain more evidence of the relationship between employability and CSCW skills, graduates were asked to complete the survey one year after they finished their degree. We wanted to give graduates time to find a job and/or graduates who already had a job the chance to experience the potential use of collaborative tools.

\subsection{Data analysis}

The analysis of the collected data was a two-phase process. First, we studied the percentages of graduate responses to the different statements for each objective in order to discuss the assessment of our three objectives.

Second, we studied the correlation among the objectives. To do this, we first performed a principal component analysis (PCA), as Objectives 1 and 3 are related to different statements. By using PCA, we were able to integrate all the available information about each objective into two new Consolidated Objectives, 1 and 3, built to capture the largest possible variance from the original data contained in the respective statements. PCA is a well-known mathematical procedure used to reduce correlated variables into a smaller number of new synthetic variables (principal components) through linear combinations of the original variables with minimum loss of information [54]. Then, we used Spearman's correlation coefficient to get the correlation values between Consolidated Objective 1, Objective 2 and Consolidated Objective 3. Spearman's correlation is a statistical measure of the strength of a monotonic relationship between paired data. Unlike Pearson's correlation coefficient, the analyzed variables do not necessarily have to be normally distributed [55]. SPSS was used to conduct the analyses.

\section{RESULTS AND DISCUSSION}

In this section, we report the results, and discuss the survey responses according to the three objectives. We then remark on how the three objectives relate to each other. 


\subsection{Benefits of using collaborative tools}

Statements related to Objective 1 check whether graduates appreciated the benefits of using collaborative tools in software development projects after studying ATIE. Looking at Figure 1, we find that the results confirm that recent graduates perceived the benefits of collaborative environments and capabilities.

Graduates confirmed that they realized that interaction and communication among team members is much better with than without collaborative environments. Also, graduates remarked that collaborative web tools provide synchronous and asynchronous communication channels among team members through forums, blogs, advertisement and announcement panels, and so on, which are helpful for software project development. They also positively rated the fact that, thanks to these communication channels, it was easier and faster to share software project knowledge, queries, files, and resources than in software projects where collaborative environments were not used.

As shown in Figure 1, graduates recognized and positively rated the benefits of using collaborative tools in software development, but very few former graduates used the Strongly agree rating. The reasons are clear from the survey comments section. Only 10 out of the 86 graduates filled out this section. The comments can be summarized as follows:

- "Unless all the members use the environment, the benefits are very small".

- "Collaborative tools are designed for use in large companies or medium-sized development groups. It could be counter-productive to use complex collaborative tools in small groups".

- "The best thing about these tools is the improvement in communication channels".

- "The collaborative tool should be well-designed and developed and it should be well-connected with the group's needs".

All these mean that the use of a CSCW per se in an organization does not guarantee the foreseen benefits; its use should be carefully planned, contextualized, and introduced, to be sure that it is applied consistently and is tailored to the organization's idiosyncrasy and characteristics.

\subsection{Finding a better job}

The second objective of the survey was aimed at checking whether knowledge of collaborative skills and tools helped recent graduates to find or improve their jobs.

Figure 2 shows that over $50 \%$ of respondents stated that their knowledge of CSCW helped them find a job. On the other hand, just under $20 \%$ disagree and another $20 \%$ do not know whether their knowledge of collaborative tools helped them to find a job. Generally speaking, however, a greater percentage of respondents confirm that there is a relationship between knowledge of CSCW and a better job. In the survey comments section, some graduates filled out the name of the company

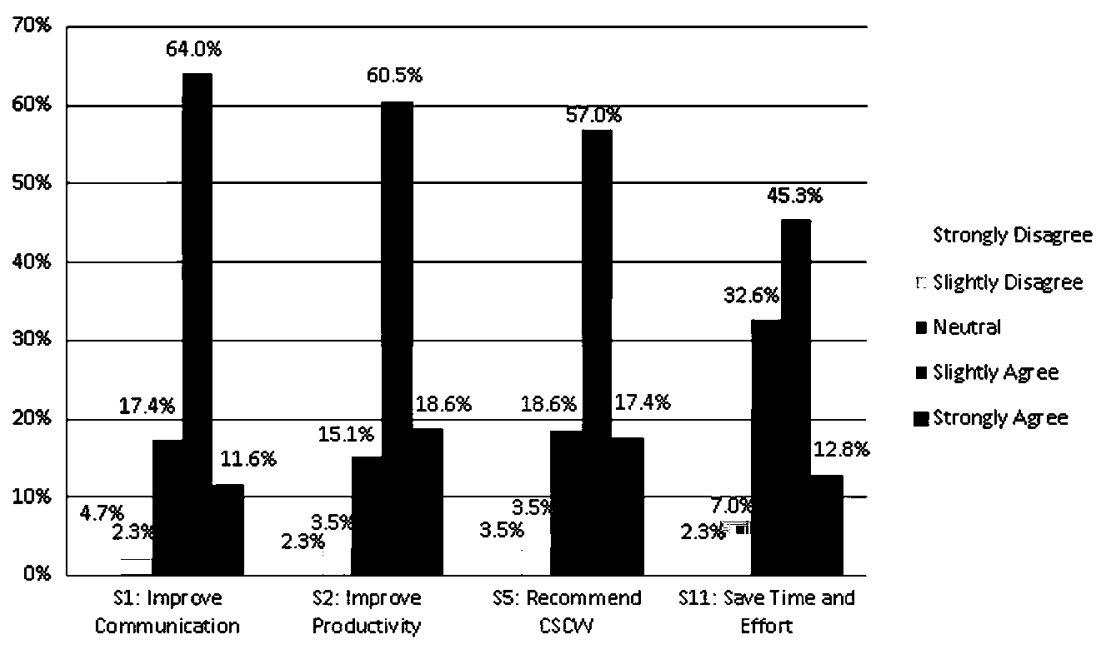

Figure 1. Benefits of using collaborative tools. 


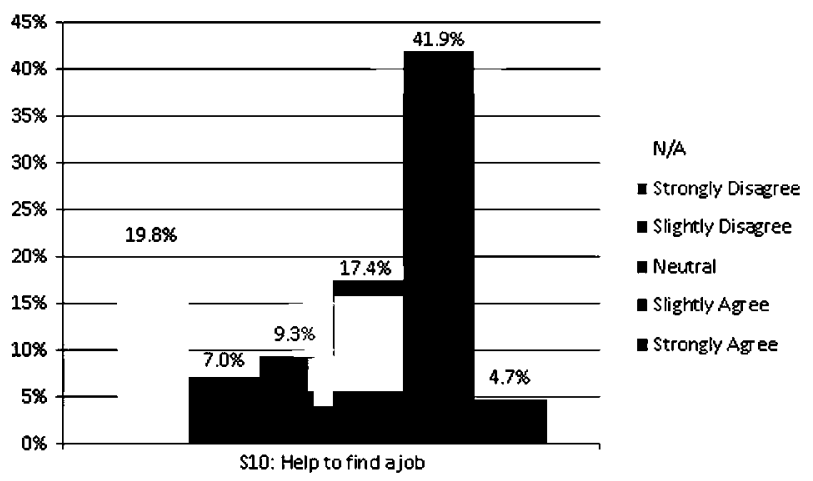

Figure 2. Relationship between collaborative skills and finding a job.

where they found the job. We find that the profile of the enterprises is heterogeneous; small, medium and large enterprises, private and public sectors.

\subsection{Enterprise attitude toward collaborative tools}

This section explores whether companies that have employed graduates on the strength of their collaborative skills really do attach importance to the benefits of these skills or whether it is just a ploy to recruit people with collaborative skills, which they then do not use in their routine work.

Looking at Figure 3, nearly $60 \%$ of respondents confirmed that enterprises do attach importance to the use of collaborative capabilities and tools in routine work. They also think that enterprises promote the use of collaborative tools because they gain improvements from using their functionalities. There were no responses in the comments section for these statements.

\subsection{Relationships between the three objectives}

We have studied the correlations among all three objectives. According to Section 3.3, as there is more than one statement examining Objectives 1 and 3 (Objective 1: S1, S2, S5, S11; Objective 3: S9, S14), we used PCA to arrive at a single value with minimum loss of information representing Objectives 1 and 3, respectively. We then applied Spearman's correlation coefficient to obtain individual correlations between pairs of parameters.

Table II shows the descriptive statistics of the three objectives. The names of the variables for Objectives 1 and 3 are referred to as Consolidated Objective 1 and Consolidated Objective 3. We find that the data for these two variables are continuous. The data for Objective 2 are taken from the Likert-scale value, as this objective was validated by only one statement.

Table III shows the results of Spearman's correlation, along with the respective $p$-values between parentheses. All correlation values are positive and significantly different from 0 , with a $p$-value $<0.05$.

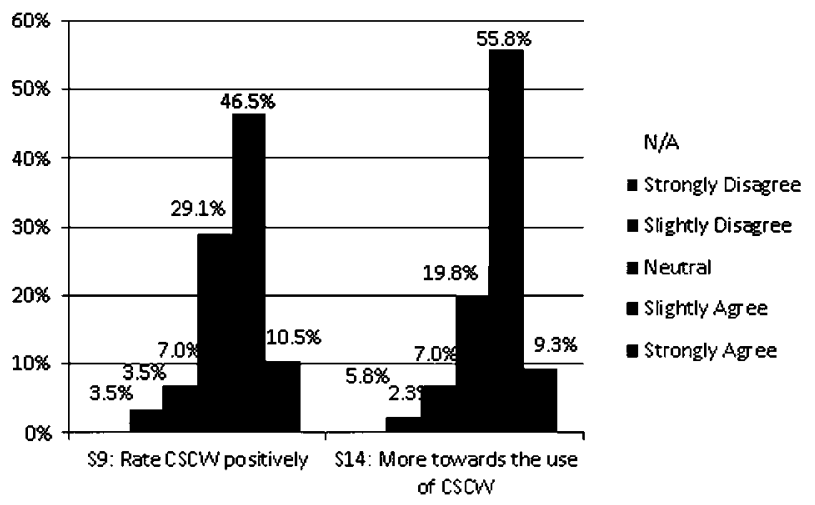

Figure 3. Importance attached by enterprises to collaborative tools. 
Table II. Descriptive statistics of all three objectives.

\begin{tabular}{lcccrr}
\hline Variable & Sample & Mean & Standard Deviation & Min & Max \\
\hline Consolidated Objective 1 & 86 & 0.000 & 1.734 & -5.824 & 2.850 \\
Objective 2 & 86 & 2.686 & 1.640 & 0.000 & 5.000 \\
Consolidated Objective 3 & 86 & 0.000 & 1.213 & -3.611 & 1.925 \\
\hline
\end{tabular}

Table III. Spearman correlation coefficients for all three objectives.

\begin{tabular}{lccc}
\hline Variables & Consolidated Objective 1 & Objective 2 & Consolidated Objective 3 \\
\hline Consolidated Objective 1 & $\mathbf{1}$ & $\mathbf{0 . 2 2 7}(0.035)$ & $\mathbf{0 . 5 5 6}(0.000)$ \\
Objective 2 & $\mathbf{0 . 2 2 7}(0.035)$ & $\mathbf{1}$ & $\mathbf{0 . 5 1 9}(0.000)$ \\
Consolidated Objective 3 & $\mathbf{0 . 5 5 6}(0.000)$ & $\mathbf{0 . 5 1 9}(0.000)$ & $\mathbf{1}$ \\
\hline
\end{tabular}

The data show that the perceived benefits of CSCW are consistent with CSCW's relationship to the chances of finding a better job and the practical use of CSCW knowledge in industry. In particular, there is a positive relationship between CSCW knowledge and the ease of finding a job. Also, we can say that enterprises promote the use of the CSCW tools in routine work, and this is related to the fact that CSCW knowledge helps practitioners to find a new or better job, that is, enterprises really do want to hire professionals with CSCW knowledge.

Negative correlations would have suggested, for example, that, even though respondents recognized the benefits of CSCW, this did not help them find a new or better job or that, even though CSCW knowledge was valuable for finding a job, it was not applied in real industry practice. This would mean that $\mathrm{CSCW}$ skills are required just as a marketing strategy.

\section{DISCUSSION AND CONCLUSION}

We developed a survey in order to rate the benefits that literature discusses about collaborative environments. The survey was completed by recent BSc in Computer Science graduates one year after they finished their degree course at UC3M.

The aims of the survey were to check if graduates appreciated the benefits of collaborative environments and capabilities for software project development. Also, we wanted to check if knowledge of collaborative skills and tools helps graduates to find a job. Finally, we checked whether collaborative tools are really used at companies or this is just an enterprise publicity or marketing strategy.

The survey was taken by BSc in Computer Science graduates from UC3M. This program is EUR-ACE (EURopean ACcredited Engineer) certified. 'The EUR-ACE® system provides a set of standards to identify high quality engineering degree programs in Europe and internationally, through the EUR-ACE® labeling system' [56][57]. This is a relevant information for discussing the generalizability of the results of this study. Generalization implies that the results would be similar if the study were replicated in different contexts, for example at different universities. Programs accredited with the EUR-ACE label are required to meet a set of common prerequisites. So, the results of this study should at least be generalizable to EUR-ACE accredited programs.

The first objective was clearly valued positively by survey respondents. They identified improvements in communication as well as productivity when using CSCW. Although the second aim is based on the subjective perception of graduates, we thought it was interesting to find out whether companies positively rate collaborative environments knowledge and capabilities at interviews with recent graduates who have no experience of but have learned CSCW at university. Although $20 \%$ of graduates answered that they did not know whether their CSCW knowledge had helped them find a job, more than 50\% thought it had, in the light of the questions that they were asked by the interviewer, and because they used a collaborative environment when they joined the companies. This outcome has major implications for universities insofar as student knowledge of 
$\mathrm{CSCW}$ is an important factor for their labor market integration, and consequently enterprises profit from their employees' CSCW knowledge in software development projects.

Reflecting on comments by respondents, we conclude that graduates should learn this kind of specialized expertise, which is clearly demanded by industry during their undergraduate studies. It is a fact that the compulsory subjects within the curricula are fixed. Therefore, new methodological and technological trends should be dynamically incorporated into the curriculum in the slots set aside for elective subjects in the senior years of degree courses. In this way, graduates will be trained in not only the general but also the specialized skills demanded by the labor market, which they will be joining after completing their studies.

This survey was anonymous, in order to ensure privacy and not to compromise alumni respondents. Anonymity has, however, placed some constraints on the study that could be improved by using information related to respondent gender, whether respondents are full-time or part-time students, and respondent $\mathrm{CSCW}$ grades. We intend to use the findings and lessons learned from this first study to develop more formal empirical studies, gathering information from graduates that have and have not taken CSCW subjects as part of their higher education. We expect to confirm our preliminary results.

The results are encouraging and support the integration of CSCW learning in computer science and software engineering curricula. For the last 20 years, one of the challenges of computer science and software engineering education has been to provide students with the knowledge and skills required in professional practice. CSCW has been identified in the literature as a relevant artifact for fulfilling business expectations, so its integration into higher education programs is a key issue. How to incorporate this knowledge into the syllabus of the different programs is another interesting subject of study, which could drive future research analyzing representative higher education programs in the field in order to identify best practices and lessons learned regarding this integration.

\section{APPENDIX A}

Data gathered for statements. Each row represents each of the graduates who responded to the questionnaire and the columns describe each of the questionnaire items.

Table AI Data gathered for statements.

\begin{tabular}{|c|c|c|c|c|c|c|c|}
\hline Id & S1 & $\mathrm{S} 2$ & S5 & $\mathrm{S} 10$ & S11 & $\mathrm{S} 12$ & S15 \\
\hline 1 & 4 & 4 & 5 & 4 & 0 & 5 & 4 \\
\hline 2 & 3 & 3 & 3 & 3 & 0 & 3 & 3 \\
\hline 3 & 4 & 3 & 4 & 3 & 0 & 3 & 3 \\
\hline 4 & 4 & 4 & 4 & 4 & 4 & 5 & 4 \\
\hline 5 & 4 & 4 & 3 & 4 & 4 & 4 & 4 \\
\hline 6 & 4 & 4 & 5 & 3 & 1 & 3 & 3 \\
\hline 7 & 4 & 4 & 5 & 4 & 0 & 4 & 3 \\
\hline 8 & 4 & 5 & 4 & 4 & 3 & 4 & 4 \\
\hline 9 & 3 & 4 & 3 & 4 & 3 & 2 & 3 \\
\hline 10 & 4 & 4 & 4 & 0 & 0 & 4 & 4 \\
\hline 11 & 4 & 4 & 5 & 3 & 0 & 5 & 3 \\
\hline 12 & 5 & 4 & 5 & 4 & 0 & 5 & 4 \\
\hline 13 & 3 & 4 & 5 & 4 & 4 & 3 & 4 \\
\hline 14 & 4 & 4 & 4 & 4 & 0 & 4 & 4 \\
\hline 15 & 4 & 4 & 4 & 4 & 0 & 3 & 5 \\
\hline 16 & 1 & 1 & 2 & 2 & 2 & 2 & 2 \\
\hline 17 & 4 & 4 & 4 & 0 & 0 & 4 & 4 \\
\hline 18 & 1 & 1 & 1 & 1 & 0 & 3 & 1 \\
\hline 19 & 4 & 4 & 4 & 0 & 0 & 4 & 3 \\
\hline 20 & 4 & 4 & 4 & 3 & 4 & 3 & 4 \\
\hline
\end{tabular}


Table AI (Continued)

\begin{tabular}{|c|c|c|c|c|c|c|c|}
\hline Id & S1 & S2 & S5 & S10 & S11 & $\mathrm{S} 12$ & S15 \\
\hline 21 & 4 & 3 & 4 & 4 & 4 & 4 & 4 \\
\hline 22 & 4 & 4 & 3 & 5 & 0 & 4 & 4 \\
\hline 23 & 4 & 4 & 4 & 4 & 4 & 4 & 4 \\
\hline 24 & 4 & 5 & 4 & 5 & 3 & 4 & 5 \\
\hline 25 & 5 & 4 & 4 & 3 & 3 & 4 & 4 \\
\hline 26 & 3 & 4 & 4 & 4 & 4 & 3 & 4 \\
\hline 27 & 3 & 4 & 4 & 3 & 3 & 3 & 3 \\
\hline 28 & 4 & 4 & 4 & 4 & 4 & 3 & 4 \\
\hline 29 & 4 & 5 & 4 & 4 & 4 & 4 & 4 \\
\hline 30 & 5 & 5 & 5 & 3 & 4 & 4 & 4 \\
\hline 31 & 4 & 3 & 4 & 3 & 4 & 3 & 4 \\
\hline 32 & 4 & 4 & 4 & 4 & 4 & 4 & 4 \\
\hline 33 & 4 & 4 & 5 & 4 & 5 & 4 & 5 \\
\hline 34 & 1 & 2 & 1 & 1 & 1 & 1 & 1 \\
\hline 35 & 3 & 3 & 3 & 3 & 3 & 3 & 3 \\
\hline 36 & 2 & 2 & 2 & 2 & 2 & 2 & 2 \\
\hline 37 & 3 & 3 & 3 & 3 & 3 & 3 & 3 \\
\hline 38 & 3 & 3 & 3 & 3 & 3 & 3 & 3 \\
\hline 39 & 4 & 4 & 4 & 4 & 4 & 4 & 4 \\
\hline 40 & 4 & 5 & 4 & 4 & 4 & 3 & 4 \\
\hline 41 & 5 & 4 & 3 & 3 & 4 & 3 & 4 \\
\hline 42 & 4 & 5 & 4 & 3 & 4 & 4 & 4 \\
\hline 43 & 1 & 2 & 1 & 2 & 2 & 2 & 2 \\
\hline 44 & 4 & 3 & 4 & 3 & 4 & 3 & 4 \\
\hline 45 & 5 & 4 & 5 & 4 & 5 & 4 & 5 \\
\hline 46 & 4 & 4 & 4 & 4 & 4 & 4 & 4 \\
\hline 47 & 4 & 4 & 4 & 4 & 4 & 4 & 4 \\
\hline 48 & 5 & 4 & 4 & 5 & 4 & 5 & 4 \\
\hline 49 & 4 & 4 & 4 & 4 & 4 & 4 & 4 \\
\hline 50 & 2 & 3 & 2 & 3 & 2 & 3 & 2 \\
\hline 51 & 4 & 3 & 3 & 3 & 3 & 3 & 3 \\
\hline 52 & 4 & 3 & 4 & 3 & 4 & 3 & 4 \\
\hline 53 & 4 & 5 & 4 & 4 & 5 & 4 & 4 \\
\hline 54 & 4 & 5 & 4 & 4 & 4 & 4 & 4 \\
\hline 55 & 4 & 4 & 4 & 4 & 2 & 4 & 4 \\
\hline 56 & 4 & 5 & 4 & 3 & 3 & 3 & 3 \\
\hline 57 & 4 & 5 & 4 & 5 & 4 & 5 & 4 \\
\hline 58 & 4 & 4 & 4 & 4 & 4 & 4 & 4 \\
\hline 59 & 5 & 5 & 5 & 5 & 5 & 5 & 5 \\
\hline 60 & 4 & 4 & 4 & 4 & 4 & 4 & 4 \\
\hline 61 & 3 & 4 & 3 & 4 & 3 & 4 & 3 \\
\hline 62 & 4 & 3 & 4 & 4 & 4 & 4 & 4 \\
\hline 63 & 4 & 4 & 4 & 4 & 4 & 4 & 4 \\
\hline 64 & 4 & 4 & 4 & 4 & 4 & 4 & 4 \\
\hline 65 & 4 & 4 & 4 & 5 & 2 & 4 & 3 \\
\hline 66 & 3 & 4 & 3 & 3 & 4 & 3 & 4 \\
\hline 67 & 4 & 4 & 4 & 4 & 4 & 4 & 4 \\
\hline 68 & 5 & 5 & 5 & 4 & 4 & 3 & 4 \\
\hline 69 & 3 & 4 & 4 & 4 & 3 & 4 & 4 \\
\hline 70 & 3 & 4 & 4 & 2 & 2 & 3 & 3 \\
\hline 71 & 4 & 4 & 3 & 4 & 4 & 4 & 4 \\
\hline 72 & 3 & 3 & 3 & 3 & 3 & 3 & 3 \\
\hline 73 & 4 & 4 & 4 & 4 & 4 & 4 & 4 \\
\hline 74 & 4 & 4 & 3 & 2 & 1 & 2 & 2 \\
\hline 75 & 5 & 5 & 5 & 3 & 0 & 5 & 4 \\
\hline 76 & 4 & 5 & 5 & 5 & 4 & 4 & 4 \\
\hline 77 & 4 & 4 & 3 & 1 & 1 & 1 & 0 \\
\hline 78 & 4 & 4 & 4 & 5 & 0 & 5 & 5 \\
\hline 79 & 4 & 4 & 4 & 3 & 0 & 3 & 0 \\
\hline
\end{tabular}

(Continues) 
Table AI (Continued)

\begin{tabular}{cccccccc}
\hline Id & S1 & S2 & S5 & S10 & S11 & S12 & S15 \\
\hline 80 & 3 & 4 & 3 & 3 & 1 & 2 & 2 \\
81 & 4 & 4 & 4 & 3 & 2 & 3 & 0 \\
82 & 4 & 5 & 4 & 5 & 3 & 5 & 5 \\
83 & 5 & 5 & 5 & 4 & 0 & 5 & 0 \\
84 & 4 & 4 & 4 & 2 & 3 & 5 & 5 \\
85 & 4 & 4 & 5 & 4 & 4 & 4 & 0 \\
86 & 3 & 4 & 4 & 4 & 1 & & 5 \\
\hline
\end{tabular}

\section{ACKNOWLEDGEMENTS}

This research was partially funded as part of Spanish Ministry of Science and Technology project no. TIN2011-27244.

\section{REFERENCES}

1. Simpson J, Weiner E. Oxford English Dictionary, 2nd edn. Oxford University Press: Oxford, UK, 1989.

2. Tschang FT, Della-Senta T. Access to Knowledge. New Information Technologies and the Emergence of the Virtual University (1st ed.). Elsevier Science Ltd: Oxford, 2001.

3. Bowers JM, Benford S. Studies in Computer Supported Cooperative Work: Theory, Practice, and Design. NorthHolland: Amsterdam, 1991.

4. Riemer K. The market for E-collaboration systems-identification of system classes using cluster analysis. In Proceedings of the Fifteenth European Conference on Information Systems St Gallen, Switzerland, 2007; 346-357.

5. Cammarinha-Matos LM, Picard W. Pervasive Collaborative Networks. Springer: New York, NY, USA, 2008.

6. Jussila JJ, Kärkkäinen H, Aramo-Immonen H. Social media utilization in business-to business relationships of technology industry firms. Computers in Human Behaviour 2014; 30:606-613.

7. Kaplan AM, Haenlein M. Users of the world, unite! The challenges and opportunities of social media. Business Horizons 2010; 53(1):59-68.

8. Jahn K, Nielsen PA. A vertical approach to knowledge management. International Journal of Human Capital and Information Technology Professionals 2011; 2(2):26-36.

9. Curry R, Kiddle C, Markatchev N, Simmonds R, Tingxi T, Arlitt M, Walker B. Facebook meets the virtualized enterprise. In Proceedings of $12^{\text {th }}$ International IEEE Conference on Enterprise Distributed Object Computing 2008; 286-292.

10. Bughin J, Chui M, Miller A. How companies are benefiting from Web 2.0. McKinsey Quatertly, 2009.

11. Heyman P. Creating a Culture of Collaboration. Bridging associates, 2010.

12. Kozlowski SWJ, Ilgen DR. Enhancing the effectiveness of work groups and teams. Psychological Science in the Public Interest 2006; 7(3):77-124.

13. IBM. Collaborative software development: a new approach: open commercial software development and jazz, 2006. (Available from: http://www-01.ibm.com/software/info/features/collaboration/main.html.) [17 November 2014]

14. Frost \& Sullivan Meetings around the world: the impact of collaboration on business performance. A Frost \& Sullivan white paper sponsored by Verizon Business and Microsoft, 2006.

15. Akoumianakis D, Ktistakis G, Vlachakis G, Zarvas P, Alexandraki C. Collaborative music making as 'remediated' practice. 18th International Conference on Digital Signal Processing 2013; 1-8.

16. Bolton A, Seals CD. Social networking and culturally situated design teaching tools: providing a collaborative environment for K-12. Human interface and the management of information. Information and interaction for learning, culture, collaboration and business. 15th International Conference, HCI International 2013; 21-26.

17. Sutcliffe A. Analysing social computing requirements with small group theory. First International Workshop on Requirements Engineering for Social Computing 2011; 18-21.

18. Cabitza F. Computational coordination mechanisms: a tale of a struggle for flexibility. Computer Supported Cooperative Work 2013; 22(4-6):475-529.

19. Khairuddin NN. Interface design for a real-time collaborative editing tool. Learning and Collaboration Technologies. Technology-Rich Environments for Learning and Collaboration. First International Conference LNCS 2014; 8524: $417-428$.

20. Wei L, Yongqi L. The Sino-Italian collaborative design platform: designing and developing an innovative product service system. Cross-Cultural Design LNCS 2014; 8528:766-774.

21. Zou B. Research and development of visual collaborative process design platform based on SOA. Modular Machine Tool \& Automatic Manufacturing Technique 2013; 7:115-117.

22. Bolton A, Seals CD. Social networking and culturally situated design teaching tools: providing a collaborative environment for K-12. Human Interface and the Management of Information. Information and Interaction for Learning, Culture, Collaboration and Business Lecture Notes in Computer Science 2013; 8018: 3-8. 
23. Kaasinen A. Mobile advertising model in $\mathrm{N}$-screen environment for CSCW. Journal of Next Generation Information Technology $2013 ; 4(2): 87-98$.

24. Molina A. Metamodel-driven definition of a visual modeling language for specifying interactive groupware applications: an empirical study. The Journal of Systems and Software 2013; 86(7):1772-1789.

25. Sheng H, Zuo H, Xu J. Study on agent collaborative work model of aircraft spares support based on CSCW environment. Information Technology Joumal 2013; 12(11):2213-2218.

26. Urena R, Herrera-Viedma E. Web 2.0 tools to support decision making in enterprise contexts. Modeling Decisions for Artificial Intelligence LNCS 2013; 8234:82-93.

27. Viana Lima C, Antunes M, Gomes D, Aguiar R. A context-aware framework for CSCW applications in enterprise environments. IADIS International Conference Web Based Communities and Social Media 2013 and IADIS International Conference Collaborative Technologies 2013; 11-18.

28. Grasso A, Convertino G. Collective intelligence in organizations: tools and studies. Computer Supported Cooperative Work 2012; 21(4-5):357-369.

29. Katzlinger E, Herzog MA. Wiki based collaborative learning in interuniversity scenarios. Electronic Journal of e-Learning 2014; 12(2):149-160.

30. Silveira Sonego AH, Hoff do Amaral EM, Becker Nunes F, Bierhalz Voss G. Use of Moodle as a tool for collaborative learning: a study focused on wiki. IEEE-RITA Latin American Learning Technologies Journal 2014; 9(1):17-21.

31. Parra JL. Developing technology and collaborative group work skills: supporting student and group success in online and blended courses. Increasing Student Engagement and Retention in e-Learning Environments: Web 2.0 and Blended Learning Technologies (Cutting-Edge Technologies in Higher Education, Wankel, C, Blessinger P (eds.). Emerald Group Publishing Limited: United Kingdom, 2013; 6:287-337.

32. Liu L, Jia Q. Research on education and training oriented virtual collaborative training environment. Proceedings 2010 Second International Conference on Computer Modeling and Simulation (ICCMS), 2010; 169-172.

33. Hu HJ, Zeng MM. The research and design of distance education system based on CSCW technology. Applied Mechanics and Materials 2013; 263-266:3448-3452.

34. Abd Aziz PNR, Md Tap AO, Mahmud M. Computer-supported cooperative work in Malaysian homestay industry. 5th International Conference on Information and Communication Technology for the Muslim World (ICT4M) 2013; 1-5.

35. Iqbal R, Shah N, James A, Cichowicz T. Integration, optimization and usability of enterprise applications. Journal of Network and Computer Applications 2013; 36(6):1480-1488.

36. Jung JJ. Contextual synchronization for efficient social collaborations in enterprise computing: a case study on TweetPulse. Concurrent Engineering: Research and Applications 2013; 21(3):209-216.

37. Michaelides R, Morton SC, Michaelides Z, Lyons AC, Liu WS. Collaboration networks and collaboration tools: a match for SMEs? International Journal of Production Research 2013; 51(7):2034-2048.

38. Requena-Carrion J, Alonso-Atienza F, Guerrero-Curieses A, Rodriguez-Gonzalez AB. A student-centered collaborative learning environment for developing communication skills in engineering education. IEEE Education Conference and Engineering 2010; 783-786.

39. Ackerman MS, Dachtera J, Pipek V, Wulf V. Sharing knowledge and expertise: the CSCW view of knowledge management. Computer Supported Cooperative Work-The Journal of Collaborative Computing 2013; 22(4-6):531-573.

40. Prescott B, Downing J, Di Maio M, How J. Using SharePoint to manage and disseminate fusion project information: an ITER case study. Fusion Engineering and Design 2013; 85(3-4):571-578.

41. Higgins J. Benefits of using online collaborative tools for project teams. Collegiate Project Services. A Cornelius \& associates company, 2007.

42. Butler M. The business value of collaboration. Best practice, benefits, costs and risks. Business Value Series 2009; 3:1-13.

43. Stanoevska-Slabeva K, Blijsma M, Gareis K, Vartiainen M, Verbug R. Collaborative work: globalization and new collaborative working environments. European Commission 2009; 1-150.

44. Harbrinder K. Studying collaboration to improve collaboration 2013. (Available from: http://blogs.cisco.com/collaboration/studying-collaboration-to-improve-collaboration/.) [17 November 2014]

45. Han K, Bennett V, Repenning A. Inspiring collaborative benefits: an interaction between a virtual and a physical group learning infrastructure. 10 Proceedings of the 15th Western Canadian Conference on Computing Education 2010; 16.

46. Moalosi WTS. Cultural concepts of learning and development. International Journal of Scientific Research in Education 2012; 5(4):287-291.

47. Selvadurai S, Choy EA, Maros M. Generic skills of prospective graduates from the employers' perspectives. Asian Social Science 2012; 8(12):295-303.

48. Tellioglu H, Diesenreiter S. Enterprise 2.0 in action: potentials for improvement of awareness support in enterprises. $9^{\text {th }}$ IEEE International Conference on Collaborative Computing: Networking, Applications and Work Sharing (Collaborate Com 2013) 2013; 485-494.

49. Nevgi A, Virtanen P, Niemi H. Supporting students to develop collaborative learning skills in technology-based environments. British Journal of Educational Technology 2006; 37(6):937-947.

50. Hairi N, Abdul A, Helma R, Che A, Abd K. Graduates' employability skills based on current job demand through electronic advertisement. Asian Social Science 2012; 8(9):103-110.

51. SE: Software Engineering. Curriculum guidelines for undergraduate degree programs in SE, ACM/IEEE CS Joint Task Force on Computing Curricula, ACM Press, 2004. (Available from: http://www.acm.org/education/curricula.html.) [17 November 2014] 
52. GSwE: Graduate Software Engineering. Curriculum guidelines for graduate degree programs in software engineering. Integrated Software and Systems Engineering Curriculum Project, Stevens Institute of Technology, A. Pyster, ed. 2009. (Available from: http://www.gswe2009.org.) [17 November 2014]

53. Medina-Dominguez F, Sanchez-Segura M, Mora-Soto A, Amescua A. Reverse engineering and software products reuse to teach collaborative web portals: a case study with final-year computer science students. IEEE Transactions on Education 2009; 53(4):595-607.

54. Hair JF, Anderson RE, Tatham RL, Black WC. Multivariate Data Analysis, 7th edn. Prentice Hall International: Englewood, 1998.

55. Triola MF. Essentials of Statistics. Pearson Addison Wesley: Boston, 2008.

56. ENAEE. Who can award the EUR-ACE® label? 2012. (Available from: http:/www.enaee.eu/wp-content/uploads/ 2012/01/pocket_broch_WEB-version_corr-version-Oct-2012.pdf.) [17 November 2014]

57. EUR-ACE. EURopean Accredited Engineer 2014. (Available from: http:/www.enaee.eu/eur-ace-system/benefits-ofthe-eur-ace-label/benefits-for-engineering-students-and-graduates.) [17 November 2014] 